\title{
Management of chronic obstructive pulmonary disease-A position statement of the South African Thoracic Society: 2019 update
}

\author{
Mohamed Sabeer Abdool-Gaffar ${ }^{1}$, Gregory Calligaro ${ }^{2}$, Michelle Lianne Wong ${ }^{3}$, Clifford Smith ${ }^{4}$, \\ Umesh Gangaram Lalloo ${ }^{5}$, Coenraad Frederik Nicolaas Koegelenberg ${ }^{6}$, Keertan Dheda ${ }^{2,7,8}$, \\ Brian William Allwood ${ }^{6}$, Akhter Goolam-Mahomed ${ }^{9}$, Richard Nellis van Zyl-Smit $^{2}$
}

${ }^{1}$ Kingsway Hospital, Amanzimtoti, Kwa Zulu-Natal, South Africa; ${ }^{2}$ Division of Pulmonology and UCT Lung Institute, Department of Medicine, Groote Schuur Hospital and University of Cape Town, Cape Town, South Africa; ${ }^{3}$ Division of Pulmonology, Chris Hani Baragwanath Academic Hospital and Faculty of Health Sciences, University of the Witwatersrand, Johannesburg, South Africa; ${ }^{4}$ Morningside Mediclinic, Sandton, Johannesburg, South Africa; ${ }^{5}$ Durban University of Technology, Enhancing Care Foundation and Busamed Gateway Private Hospital, Kwa Zulu-Natal, South Africa; ${ }^{6}$ Division of Pulmonology, Department of Medicine, Stellenbosch University and Tygerberg Hospital, Cape Town, South Africa; ${ }^{7}$ Centre for Lung Infection and Immunity, Division of Pulmonology, Department of Medicine and UCT Lung Institute \& South African MRC/UCT Centre for the Study of Antimicrobial Resistance, University of Cape Town, Cape Town, South Africa; ${ }^{8}$ Faculty of Infectious and Tropical Diseases, Department of Infection Biology, London School of Hygiene and Tropical Medicine, London, UK; ${ }^{9}$ Louis Pasteur Private Hospital and Mediclinic Pretoria Heart Hospital, Pretoria, South Africa

Correspondence to: Richard Nellis van Zyl-Smit. Division of Pulmonology and UCT Lung Institute, Department of Medicine, Groote Schuur Hospital and University of Cape Town, Cape Town, South Africa. Email: richard.vanzyl-smit@uct.ac.za.

Submitted Oct 06, 2019. Accepted for publication Oct 10, 2019.

doi: $10.21037 /$ jtd.2019.10.65

View this article at: http://dx.doi.org/10.21037/jtd.2019.10.65

\section{Introduction}

Chronic obstructive pulmonary disease (COPD) is a significant cause of death and disability in both developed and developing countries. It is increasing in frequency and demands increasing utilisation of healthcare resources.

\section{Objective}

To revise the South African guideline for the management of COPD based on emerging research that has informed updated recommendations.

\section{Key points}

(I) Smoking is the major cause of COPD, HIV infection, exposure to biomass fuels and tuberculosis are important additional factors.

(II) Spirometry is important for the diagnosis of COPD.

(III) COPD is either undiagnosed or diagnosed too late, thus limiting the benefit of therapeutic interventions; performing spirometry in at-risk individuals will help to identify COPD early.

(IV) COPD should be managed as a multisystem disease with attention to comorbidities, particularly cardiovascular disease.

(V) Primary and secondary prevention are the most cost-effective strategies in managing COPD. Smoking cessation as well as avoidance of other risk factors can prevent the development of COPD and retard disease progression.

(VI) Bronchodilators [long-acting muscarinic antagonist (LAMA) or long-acting beta-2 agonists (LABA)] are the mainstay of pharmacotherapy, relieving dyspnoea, reducing acute exacerbations, reducing rate of disease progression and improving quality of life.

(VII) Inhaled corticosteroids (ICS) are recommended in patients with frequent exacerbations and those with peripheral blood eosinophilia and have a synergistic effect with bronchodilators 
in improving lung function, quality of life and reducing exacerbation frequency.

(VIII) Oral corticosteroids are not recommended for maintenance treatment of COPD.

(IX) A therapeutic trial of oral corticosteroids to distinguish corticosteroid responders from nonresponders is not recommended.

(X) Acute exacerbations of COPD contribute significantly to health care costs, accelerates loss of lung function and increases mortality. A short course of oral corticosteroids (5 days) has been shown to be beneficial in acute exacerbations.

(XI) Antibiotics are indicated during acute exacerbations associated with purulent sputum.

(XII) Lifestyle modification, pulmonary rehabilitation $(\mathrm{PR})$, pneumococcal vaccination and annual influenza vaccination are recommended for COPD patients.

\section{Guideline development}

\section{Evidence}

A working group of clinicians and clinical researchers revised and updated the previous guidelines based on a detailed review of recent literature, particularly of studies performed in South Africa. The level of evidence supporting the recommendations are based on the 2019 GOLD guidelines (1).

\section{Benefits, harms and costs}

The position paper pays particular attention to costeffectiveness in South Africa and promotes optimal care for COPD. It promotes smoking cessation and selection of treatment based on objective evidence of benefit. It also rejects a nihilistic or punitive approach, even in those who are unable to break the smoking addiction.

\section{Recommendations}

These include primary and secondary prevention; early diagnosis, grading of severity, use of pharmacotherapy, pulmonary rehabilitation (PR), and management of complications and co-morbidities. Advice is provided on the management of acute exacerbations, prescription of long-term domiciliary oxygen, guidelines for air travel, indication for lung volume reduction surgery (LVRS) and lung transplantation (LT).

\section{Validation}

The COPD Working Group comprised experienced pulmonologists representing University departments in South Africa and from private practice.

\section{Definition}

COPD is a defined by GOLD as: " $A$ common, preventable and treatable disease, that is characterized by persistent respiratory symptoms and airflow limitation that is due to airway and/or alveolar abnormalities usually caused by significant exposure to noxious particles or gases." "The chronic airflow limitation that is characteristic of COPD is caused by a mixture of small airways disease and parenchymal destruction, the relative contributions of which vary from person to person." $(1,2)$.

\section{Epidemiology of COPD}

COPD is one of the leading causes of morbidity and mortality in the world. It is estimated that there are currently over 380 million cases in the world, a significant proportion of whom are undiagnosed. The prevalence of COPD is projected to rise owing to increased exposure to risk factors and population ageing $(1,3)$. A recent metaanalysis of 123 COPD studies estimated that the global prevalence was $11.7 \%(8.4-15.0 \%)$ (3). In Africa the estimated prevalence is $13.4 \%$ (IQR, $9.4 \%$ to $22.1 \%$ ) (4).

The Burden of Obstructive Lung Disease (BOLD) study (5) that investigated the prevalence of COPD in various countries showed that COPD prevalence varied considerably in different countries, with a range of $6-19 \%$ for Stage $\geq 2$ COPD (clinically significant disease) and $12-26 \%$ for Stage $\geq 1$ COPD. Cape Town had the highest prevalence of stage $\geq 2$ COPD (19\% overall, $22 \%$ male and $17 \%$ female), which may be greater than the general South African prevalence because of the higher incidence of smoking, occupational dust exposure, indoor pollution and prior tuberculosis in the area studied. Unlike other chronic diseases, COPD mortality for both men and women is increasing. The Global Burden of Disease Study has projected that COPD, which was ranked $6^{\text {th }}$ as the cause of death in 1990 , will become the third leading cause of death by $2020(6,7)$.

\section{Risk factors}

Tobacco smoking is the most prevalent aetiological factor for COPD. However non-tobacco related factors and the interactions with tuberculosis, HIV, and biomass smoke 
play important roles (8). This is especially important in low income countries and may even supersede the effect of tobacco smoke where tobacco smoking is uncommon. Both genetic susceptibility and environmental exposures are important.

\section{Host}

\section{Genetic}

Alpha-1 antitrypsin deficiency (AATD) is a rare but well characterised genetic risk factor (9). Although many genes have been associated with COPD-none other than AATD have been directly causally linked $(10,11)$. There is, however, a familial tendency for COPD in smoking family members highlighting the importance of the gene $v$ s. exposure link (12).

\section{Lung growth and development}

Early childhood and even in utero exposures are recognised as important predictors of peak lung volumes and the subsequent development of COPD. Maternal tobacco smoking, malnutrition, poor lung growth owing to problems in utero and exposure during childhood is associated with airflow obstruction in adulthood $(13,14)$.

\section{Gender}

COPD prevalence and mortality is greater among men than women, and reflects previous smoking patterns. The prevalence is now equalising in developed countries. Women may be more susceptible than men to the effects of tobacco smoke (15).

\section{Environment}

\section{Inhalational exposure \\ Tobacco smoke}

COPD is more common in smokers and ex-smokers than in non-smokers. Cigarette smokers have more respiratory symptoms, lung function abnormalities, faster decline in $\mathrm{FEV}_{1}$, and COPD mortality than non-smokers. The starting age, total pack-years smoked and current smoking status are predictive of COPD morbidity and mortality (16). The annual decline of forced expiratory volume in one second $\left(\mathrm{FEV}_{1}\right)$ in smokers varies from 55-100 vs. about 30 $\mathrm{mL} /$ year in non-smokers (17). However, not all smokers develop clinically significant COPD so genetic factors must modify risk (18). The oft-quoted figure of only $15 \%$ of smokers developing COPD is probably an under-estimate
(19). Pipe and cigar smokers have greater COPD morbidity and mortality rates than non-smokers, although their rates are lower than those for cigarette smokers. Passive or environmental tobacco smoke (ETS) may also contribute to COPD (20,21). Smoking during pregnancy may predispose to asthma and COPD by decreasing lung growth and development in the foetus (22).

\section{Cannabis}

Smoking cannabis is associated with higher frequency of chronic bronchitis and a dose-related airflow obstruction especially when combined with tobacco $(23,24)$.

\section{Occupational dusts and chemicals}

Occupational dust and chemical exposure has long been identified as an independent cause of COPD (25). The population-based National Health and Nutrition Examination Survey (NHANES III) utilising spirometry as far back as 2002, estimated that the fraction of COPD attributable to work was $19 \%$ overall and $31 \%$ among never-smokers (26).

\section{Indoor air pollution}

The burning of biomass and fossil fuels (wood, animal dung, crop residues and coal) in open fires or poorly functioning stoves in poorly ventilated spaces lead to very high levels of indoor air pollution. Almost half the world's population, and $90 \%$ of rural families use biomass or coal as their main source of energy for cooking and heating resulting in over 3 billion people exposed $(27,28)$. Biomass exposure begins in early childhood and may continue throughout life with significant negative health effects including COPD $(29,30)$. There remains some controversy over the definition of biomass induced chronic lung disease (31).

\section{Outdoor air pollution}

Environment air pollution, mainly from motor vehicle emissions in cities and biomass smoke (from bush and forest fires), is associated with loss of lung function (32-34).

\section{Infections}

There is now unequivocal evidence of the association between previous tuberculosis and COPD (35-37), which in many settings is stronger than the association between smoking and COPD (38-40). The mechanism of chronic airflow limitation is likely to involve the small airways primarily, and may be distinct from smoking related COPD $(41,42)$; however, the two conditions may co-exist within an individual. The association between tuberculosis and COPD is strongest in high incidence countries, the young and never smokers $(35,37)$. Post-tuberculosis 
bronchiectasis should be excluded as a cause of airflow limitation, before tuberculosis-associated obstruction is presumed.

Childhood respiratory infections are associated with reduced lung function and increased respiratory symptoms in adulthood (43). Several studies have shown that previous pulmonary tuberculosis may lead to COPD (44). HIV infection has been shown to accelerate the onset of smoking-related emphysema $(45,46)$. In addition, viral and bacterial infections may contribute to the pathogenesis and progression of COPD (47).

Table 1 Distinguishing features of chronic obstructive pulmonary disease (COPD) and asthma

\section{Features suggesting a diagnosis of COPD \\ - Persistent dyspnoea on effort with cough and wheeze \\ - History of smoking or exposure to other risk factors \\ - Slow progression}

- Abnormal post bronchodilator spirometry

Features that suggest the presence of asthma

- Young age at onset

- Diurnal or day-to-day variability and seasonal variation

- Presence of atopy and/or allergic rhinitis

- Significant bronchodilator responsiveness

Additional considerations in the diagnosis of asthma and COPD

- Asthma and COPD may co-exist, and distinguishing them may be difficult

- Asthmatics who smoke may have an accelerated decline in lung function

- COPD patients may have a raised eosinophil count and bronchodilator responsiveness

COPD, chronic obstructive pulmonary disease.

\section{Socioeconomic status}

Poor socio-economic status is strongly linked to COPD and likely promoted by smoking, biomass exposure, poor nutrition, and intrauterine growth retardation (48).

\section{Aim of this position paper}

The purpose of this paper is to improve the care of patients with COPD at all levels of the health system in South Africa and to provide information that will assist in early recognition and optimal treatment $(49,50)$.

\section{Recognition of disease (early diagnosis and staging of severity)}

The diagnosis of COPD should be considered in any patient with chronic progressive dyspnoea and/or chronic cough (with or without sputum production) with a smoking history of more than 10 pack-years and/or other risk factors for COPD. A detailed history of exposure during childhood, occupation, as well as tobacco, HIV and previous TB is important. All smokers should be considered at risk and have screening spirometry where this is available.

Correct diagnosis, and in particular the differentiation of COPD from other causes of patient's symptoms, is important to ensure correct treatment. Clinical features that assist in the diagnosis of each condition are outlined in Table 1. Early detection of COPD, effective smoking cessation interventions, optimal pharmacotherapy, lifestyle modification and PR slow the decline in pulmonary function and improve the quality of life.

Clinical evaluation should include a history of exposures and risk factors, an assessment of breathlessness (e.g., the modified MRC dyspnoea scale (Figure 1), symptoms [COPD Assessment Test (CAT)] (Figure 2), the occurrence and severity of exacerbations, and co-morbid conditions

\begin{tabular}{ll}
\hline Grade & Description \\
\hline 0 & Not troubled by breathlessness except with strenuous exercise \\
1 & Troubled by shortness of breath when hurrying on the level or walking up a slight hill \\
2 & $\begin{array}{l}\text { Walks slower than people of the same age on the level because of breathlessness or } \\
\text { has to stop for stop for breath when walking at own pace }\end{array}$ \\
3 & Stops for breath after walking about 100 m or after a few minutes on the level \\
4 & Too breathless to leave the house or breathless when dressing or undressing \\
\hline
\end{tabular}

Figure 1 Modified Medical Research Council (UK) dyspnoea scale. 


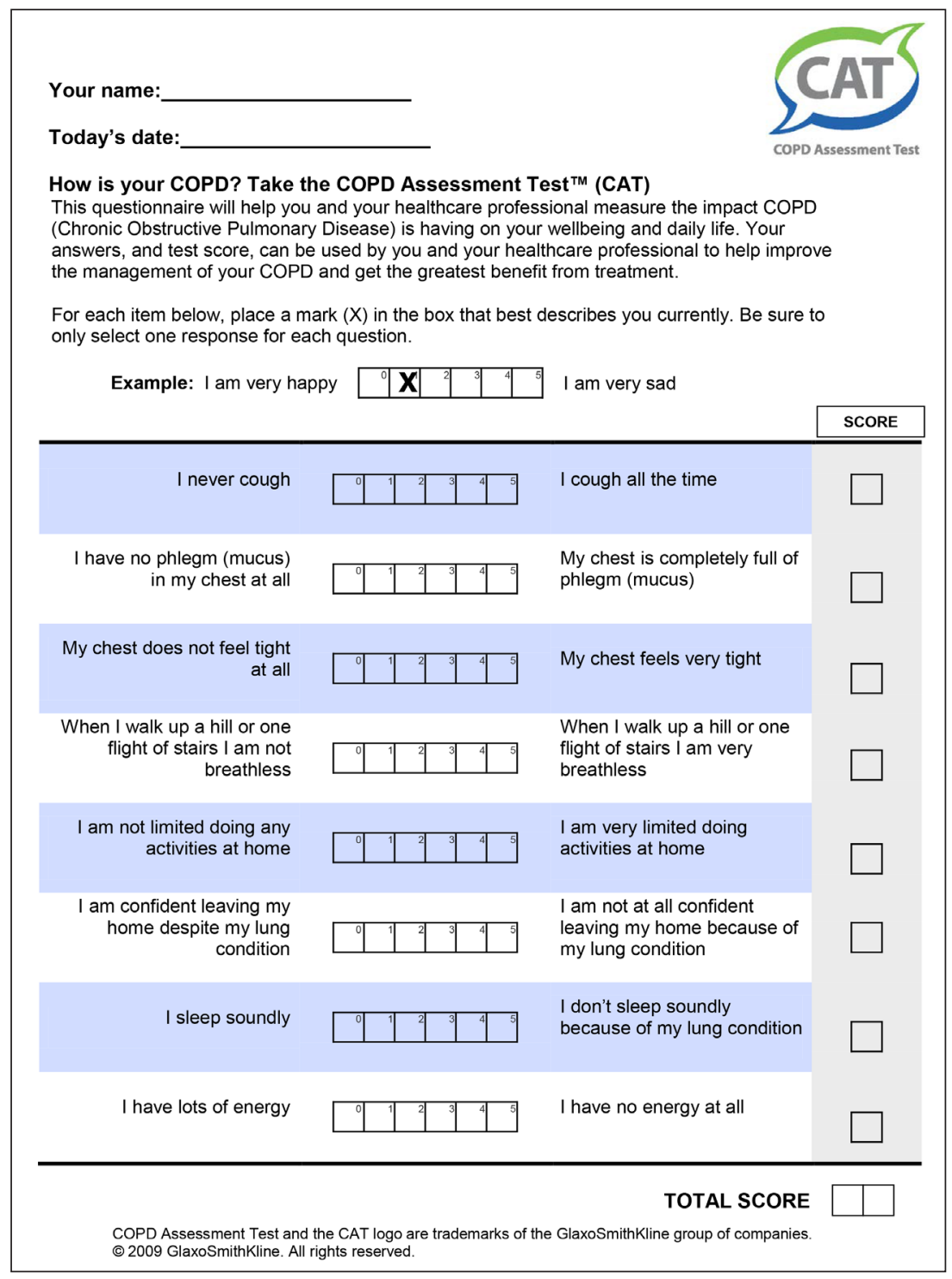

Figure 2 CAT is reproduced with permission from GSK.

that could complicate management. Physical examination may reveal signs of hyperinflation and airway obstruction but may be normal. Co-morbid conditions should also be sought.

\section{Spirometry}

Spirometry is critical for the detection, assessment and management of patients with COPD. It is encouraged and must be performed by adequately trained persons using a spirometer of approved standard and quality that is calibrated frequently (51). Measurements used in the diagnosis of COPD are pre- and post-bronchodilator $\mathrm{FEV}_{1}$, $\mathrm{FVC}$ and $\mathrm{FEV}_{1} / \mathrm{FVC} \%$.

\section{Detection of airflow obstruction}

The presence of a post-bronchodilator $\mathrm{FEV}_{1} / \mathrm{FVC}$ ratio of less than $70 \%$ confirms the presence of airflow obstruction. The $\mathrm{FEV}_{1}$ is usually reduced (less than $80 \%$ of predicted value) and is used as a measure of severity. Most patients with symptomatic COPD have a reduced 
Table 2 Grading of the severity of airflow limitation

\begin{tabular}{lcc}
\hline Severity grade & Severity grade & FEV $^{*}{ }^{*} \mathrm{FEV}_{1} \geq 80 \%$ of predicted \\
\hline 1 & Mild & $50 \% \leq \mathrm{FEV}_{1}<80 \%$ of predicted \\
2 & Moderate & $30 \% \leq \mathrm{FEV}_{1}<50 \%$ of predicted \\
3 & Severe & $\mathrm{FEV}_{1}<30 \%$ of predicted \\
\hline
\end{tabular}

${ }^{*}$, post bronchodilator $\mathrm{FEV}_{1}$. $\mathrm{FEV}_{1}$, forced expiratory volume in one second.

$\mathrm{FEV}_{1}$, but many patients with significantly reduced $\mathrm{FEV}_{1}$ have no symptoms.

\section{Assessment of bronchodilator responsiveness with short- acting bronchodilators}

Spirometry should be performed before, and 10 to 30 minutes after, 4 puffs of a short-acting beta ${ }_{2}$-agonist bronchodilator (e.g., salbutamol). An improvement in $\mathrm{FEV}_{1}$ $\geq 12 \%$ from baseline and $\geq 200 \mathrm{~mL}$ indicates significant bronchodilator responsiveness. Larger bronchodilator responses $(>400 \mathrm{~mL})$ are suggestive of asthma but are also seen in many patients with COPD (52). However, in general, the larger the improvement, the greater the likelihood that the diagnosis is asthma, however this cannot be used as the sole diagnostic criteria for asthma and the clinical profile should be borne in mind (Table 1). Normalisation of spirometry after a bronchodilator excludes the diagnosis of COPD.

\section{Assessment of severity of COPD}

To establish the severity of airflow obstruction, $\mathrm{FEV}_{1}$ is expressed as a percentage of predicted values. The European Community for Steel and Coal (ECSC) (53) or the NHANES III reference equations (54) are recommended for routine use in South Africa, but the newer Global Lung Initiative (GLI) equations are becoming more widely used (55). The validity and appropriateness of the correction for ethnicity is an area of much debate currently. Caution should be exercised when borderline lung function values are elicited before labelling an individual with disease. The GLI equations, using lower limits of normal or suggested correction factors for ethnic differences (amounting to approximately $12 \%$ lower values for FVC in Africans or AfricanAmericans) have been reported in some series, and a correction factor (multiplication of the spirometric value by 0.9 for African blacks and 0.95 for people of mixed or Asian ethnicity) could be applied (56). Measurement of peak expiratory flow (PEF), while helpful in asthma, is not an appropriate test for diagnosing COPD and does not distinguish obstructive from restrictive lung disease.

The assessment of severity of COPD is based on spirometry measures and clinical indicators including severity of dyspnoea and symptoms, functional impairment and 6-minute walking distance (6MWD) (57). Assessment of dyspnoea (as per the mMRC score) and exacerbation history in the past twelve months as criteria to be used to grade severity is recommended to guide appropriate pharmacological treatment. Primary treatment should be with a long-acting bronchodilator to relieve dyspnoea. Additional anti-inflammatory treatment is recommended if there is a history of frequent exacerbations ( $\geq 2$ per year).

Grading of severity also guides prognosis and level of treatment. The complex 2019 GOLD algorithm has been simplified for use across all levels of care (primary to specialist level care) in South Africa. A mild, moderate and severe COPD approach has been advocated in keeping with GOLD A, B and D. Details of the grades of severity are provided in Table 2.

\section{Monitoring disease progression}

Progression of COPD is monitored using serial spirometry, dyspnoea grading and frequency of exacerbations. Rapid progression may be due to acute exacerbations or cardiac disease, pulmonary embolism and pneumothorax.

\section{Chest radiography}

A chest radiograph is recommended at the time of diagnosis of COPD. It may show evidence of hyperinflation, but a normal chest radiograph does not exclude the diagnosis. It is also useful for detecting alternative condition such as lung cancer or interstitial pulmonary fibrosis. 


\section{Prevention of disease progression}

Avoidance of occupational and environmental pollution, including passive tobacco smoke exposure is important, particularly in susceptible persons: pregnant women, infants and children, persons with alpha-1 antitrypsin deficiency, and those with established COPD.

Smoking cessation is the primary measure that has been shown to slow the progression of COPD, and is one of the most cost-effective interventions in health care (58). All smokers must be encouraged to stop smoking. Health care workers should be familiar with smoking cessation measures and promote these among their patients (59). Although respiratory symptoms may initially worsen when an individual quits, the short and long-term benefits are substantial. Of particular importance is the reduction in cardiovascular and cancer risk and the slowing of lung function decline $(60,61)$.

\section{Smoking cessation programmes}

The South African Thoracic Society clinical practice guidelines contain a detailed approach to smoking cessation in the South African context (59). For all smokers, behavioural modification is recommended in order to break the habit of smoking. For smokers with high levels of nicotine addiction, a tailored approach of either nicotine replacement therapy or targeted pharmacological therapy (varenicline or bupropion) may be more effective. Relapse is not uncommon due to the strong behavioural aspect of smoking and the addictive nature of nicotine. In individuals living in low income settings, behavioural and psychological support may be more important than just the provision of NRT (62).

\section{Alleviation of breathlessness and improvement in effort tolerance}

Inhaled therapy is the preferred route of administration of COPD medication. Inhaler technique, choice of the most appropriate device and combination of medication are essential to ensure adequate delivery of medication and reduce side effects.

\section{Bronchodilators}

Bronchodilators are the mainstay of the treatment of COPD and include inhaled beta-2 agonists and muscarinic antagonists. Oral theophylline additionally has some bronchodilator effect. Individuals vary in their responsiveness to each, and combinations may have additive effects (63-65). Commence treatment in symptomatic patients with an inhaled short-acting bronchodilator on a PRN basis (mild COPD/GOLD A). Thereafter, increase treatment stepwise to include inhaled long-acting bronchodilators, slow-release theophylline (moderate COPD/GOLD B) and ICS in those with more severe symptoms and exacerbations (severe COPD/GOLD D) (Table 3).

\section{Inhaled short-acting beta-2 agonists}

These agents have a rapid onset of action and are only of value in short-term relief of symptoms.

\section{Inbaled $L A B A$}

There are several LABAs, and are available either as single agents or in combination (salmeterol, formoterol, indacaterol, vilanterol, olodaterol). LABAs are more effective for symptom control than regular short-acting beta- 2 agonists. Their use as monotherapy is recommended in moderate COPD (GOLD B) without ICS (unlike in asthma where they must only be used in combination with an ICS). LABAs improve symptoms, reduce exacerbations, reduce rescue therapy requirements and improve exercise capacity (Evidence A) $(63,66)$.

\section{Inbaled muscarinic antagonists}

Anti-muscarinic agents are effective bronchodilators for COPD as the disease is associated with increased vagally mediated bronchoconstriction. Ipratropium bromide is a short-acting agent with a peak bronchodilator effect at approximately 40 minutes and between 4-6 hours duration of action. Tiotropium bromide is a LAMA with a slow onset of peak bronchodilation but a 24-hour duration of action facilitating once-daily administration. Glycopyrronium bromide, another once-daily LAMA, has been shown to have equivalent efficacy to tiotropium, but with a faster onset of action. Anti-cholinergic agents may be more effective than beta- 2 agonists in many patients and have few side effects but may result in a dry mouth and urinary retention.

Ipratropium bromide is prescribed for as-needed use for symptom relief in COPD and can also be used 4-6-hourly as a maintenance bronchodilator agent although it is far less effective than the once daily drugs (67). Tiotropium or glycopyrronium may be used as a first-line long-acting 
Table 3 Treatment choices based on severity of disease

\begin{tabular}{|c|c|c|}
\hline $\begin{array}{l}\text { Severity of } \\
\text { disease }\end{array}$ & Defining clinical features & Treatment recommendations \\
\hline $\begin{array}{l}\text { Mild COPD } \\
\text { (GOLD A) }\end{array}$ & $\begin{array}{l}\text { Confirmed spirometric post-bronchodilator obstruction (commonly } \\
\text { will have mild to moderate severity of lung function }\left(\mathrm{FEV}_{1}>50 \%\right)^{\mathrm{a}} \text {; } \\
\text { minimal symptoms on effort }(\mathrm{mMRC}<2), \mathrm{CAT}<10^{\mathrm{b}} \text {; infrequent } \\
\text { exacerbations ( } 1 \text { per year) }{ }^{\mathrm{c}}\end{array}$ & $\begin{array}{l}\text { Short acting bronchodilator (SABA or SAMA) as } \\
\text { needed for symptomatic relief }\end{array}$ \\
\hline $\begin{array}{l}\text { Moderate COPD } \\
\text { (GOLD B) }\end{array}$ & $\begin{array}{l}\text { Confirmed spirometric post-bronchodilator obstruction (lung } \\
\left.\text { function may be preserved or significantly reduced, } \mathrm{FEV}_{1}>50 \%\right)^{\mathrm{a}} \text {; } \\
\text { significant symptoms on effort ( } \mathrm{mMRC} \geq 2 \text { ), or CAT }>10 \text {; infrequent } \\
\text { exacerbations ( } 1 \text { per year) }\end{array}$ & $\begin{array}{l}\text { Long acting bronchodilator either LAMA or LABA; } \\
\text { if inadequate response, try alternative agent or } \\
\text { add a second bronchodilator; if no symptomatic } \\
\text { benefit, withdraw second agent }^{\mathrm{d}}\end{array}$ \\
\hline $\begin{array}{l}\text { Severe COPD } \\
\text { (GOLD D) }\end{array}$ & $\begin{array}{l}\text { Confirmed spirometric post-bronchodilator obstruction (commonly } \\
\left.\text { will have severe lung function reduction } \mathrm{FEV}_{1}<50 \%\right)^{\mathrm{a}} \text {; severe } \\
\text { symptoms on effort ( } \mathrm{mMRC} \geq 2 \text { ), CAT }>10 \text {; frequent exacerbations: } \\
2 \text { outpatient or } 1 \text { inpatient in past } 12 \text { months }\end{array}$ & $\begin{array}{l}\text { Single bronchodilator } L_{A M A}{ }^{e} \text {; dual bronchodilator: } \\
\text { LAMA/LABA or alternatively LABA/ICS ; if not } \\
\text { responding to dual agents, referral to specialist is } \\
\text { advised }^{g}\end{array}$ \\
\hline
\end{tabular}

\begin{abstract}
${ }^{a}$, lung function is not used to grade the severity of COPD or inform therapy. The severity of obstruction will provide guidance as to how severe the airflow limitation is but correlates poorly with symptoms and mortality. ${ }^{b}$, the mMRC evaluates dyspnoea on effort, and the CAT (COPD assessment test) is a composite score of symptoms including cough, dyspnoea, etc. ${ }^{c}$, exacerbations are loosely defined as significant symptoms warranting additional treatment with corticosteroids and or antibiotics. ${ }^{d}$, theophylline can be considered for moderate or severe COPD based on availability of alternative inhaled therapies. ${ }^{e}$, if Initiating therapy, start with LAMA. If previously on a single agent, use dual bronchodilator. ${ }^{\dagger}$, dual bronchodilator (LAMA/LABA) is the first-choice recommendation for dual agent, as there is a greater reduction in exacerbations compared to LABA/ICS with less risk of pneumonia [rate ratio $0.89(0.83-0.96)$ ] NNT 20 (95\% Cl, 13-44) (66). The cost of LAMA/LABA is significantly higher than LABA/ICS which should be considered in the treatment choice where resources are limited. ${ }^{9}$, in the severe group, see Table 4 for suggested 'phenotyping options' to guide add-on therapy at specialist level. COPD, chronic obstructive pulmonary disease; $\mathrm{FEV}_{1}$, forced expiratory volume in one second; mMRC, modified Medical Research Council; SABA, short acting beta-2 agonist; SAMA, short acting muscarinic antagonist; CAT, COPD Assessment Test; LAMA, long-acting muscarinic antagonist; LABA, long-acting beta-2 agonists; ICS, inhaled corticosteroids; NNT, number needed to treat.
\end{abstract}

Table 4 Treatment approach according to 'Phenotypes' in severe COPD

\begin{tabular}{ll}
\hline Clinical phenotype & Management strategy \\
\hline Dyspnoea phenotype & With increasing dyspnoea, one should increase bronchodilator therapy \\
Exacerbator phenotype & LAMA or combination long-acting bronchodilators $\rightarrow$ add on ICS and/or \\
& Roflumilast and/or a macrolide \\
Co-existing asthma (blood eosinophil count $\left.>300 / \mathrm{mm}^{3}\right)$ & Consider ICS \\
$\begin{array}{l}\text { Severe/very severe COPD + chronic bronchitis phenotype \& } \\
\text { frequent exacerbations }\end{array}$ & Consider adding roflumilast or a macrolide
\end{tabular}

COPD, chronic obstructive pulmonary disease; LAMA, long-acting muscarinic antagonist; ICS, inhaled corticosteroids.

bronchodilator treatment in COPD, or may be used in combination with a LABA because of their different mechanisms of action. LAMAs have been shown to improve quality of life and reduce exacerbation rates (Evidence A) and hospitalisation (Evidence B) $(65,68,69)$.

\section{Combination therapy}

The following combination of drugs may be considered for patients who remain symptomatic despite monotherapy or who have severe COPD or frequent exacerbations. However, combination therapy can increase costs substantially. Some combinations of inhaled drugs are available in a single inhaler device.

Compared to LABA alone the addition of a LAMA resulted in (64):

* Reduction in exacerbation rate (Evidence B);

* Small but significant improvement in SGRQ 
(Evidence A);

* Improvement in $\mathrm{FEV}_{1}$ (Evidence A).

Compared to LABA alone adding an ICS $(70,71)$ :

* Reduces the number of acute exacerbations in patients

with moderate to severe COPD (Evidence A);

* Improves $\mathrm{FEV}_{1}$ (Evidence A);

* Improves health-related quality of life (Evidence A);

* Increases the risk of oral candidiasis and pneumonia (Evidence A).

Compared to LABA/ICS the LAMA/LABA combination (FLAME study) (72):

* Reduced exacerbation rate RR 0.89 (95\% CI, 0.830.96);

* Lengthened time to first exacerbation $71 \mathrm{vs}$. 52 days (95\% CI, 46-57 days);

* Reduced pneumonia: $3.2 \%$ vs. $4.8 \%, \mathrm{P}=0.02$.

Compared to LABA/ICS, LABA/LAMA \& LAMA alone, the LABA/LAMA/ICS combination (IMPACT Study) (73):

* Increases $\mathrm{FEV}_{1}$, reduces exacerbation frequency, improves symptoms (Evidence A).

\section{Nebuliser treatment}

This is an alternative for lung function grade 3 and 4 patients with poor inhalation technique and/or acute dyspnoea.

* Nebulised ipratropium plus beta-2 agonist can be used up to 3 or more times daily $(74,75)$. While there are distinct advantages, nebulisers tend to be overused.

* Patients requiring chronic nebuliser therapy should have specialist assessment.

\section{Theophylline}

Theophylline, a methylxanthine, has similar bronchodilator effects to beta-2 agonists. It improves quality of life (Evidence B). Oral administration is an advantage for some patients (76). Limitations include toxicity (particularly in the elderly), drug interactions and variable metabolism and compared to LABAs are less effective (77). The recommended dose of oral slow-release theophylline is $200-400 \mathrm{mg}$ twice a day or $400-800 \mathrm{mg}$ at night, and should not be exceeded without monitoring blood levels. This drug should preferably be used together with inhaled bronchodilator therapy, and not as monotherapy. Combination tablets containing theophylline and other bronchodilators, or sedatives are not recommended.

\section{Inbaled corticosteroids (ICS)}

There is no conclusive evidence for the use of ICS as monotherapy in COPD $(63,70)$. In the chronic phase of COPD, corticosteroids should only be given by the inhaled route and always in combination with bronchodilators. ICS therapy has been linked to the development of pulmonary tuberculosis (78-80) and should be used in the appropriate patient group and with caution.

There continues to be controversy regarding the use of ICS in COPD but some aspects are clear: ICS therapy has been associated with an increased risk of pneumonia (Evidence A) (71). However, the absolute increase in incidence of pneumonia is $0-3 \%$ (81). When pneumonia does occur, it does not appear to be life-threatening (82-84). However, when combined with a LABA, the ICS/ LABA combination is more effective than either alone in improving lung function and health status, as well as reducing exacerbations (Evidence A) $(63,70)$. There is growing evidence of a COPD eosinophilic phenotype that responds better to ICS. It is recommended that a blood eosinophil level above 300 cells $/ \mu \mathrm{L}$ defines this responder status, with a linear relationship with higher eosinophil counts, i.e., the greater the number the greater the improvement in the exacerbation rate (85).

Adding a LAMA to LABA/ICS also improves lung function, patient reported outcomes and exacerbations (Evidence A) (73). ICS in combination with a LABA and/ or LAMA should be reserved for patients with a high probability of exacerbations during the next year (1). Moreover, ICS may be withdrawn and replaced by LABA and/or LAMA in low risk patients $(1,86)$. This should be done with caution especially in patients with high eosinophils or a history of asthma and where an initial decline in lung function is expected $(86,87)$.

\section{Oral corticosteroids}

The long-term use of oral corticosteroids is strongly discouraged given its poor impact on lung function (Evidence C) and major side-effects (Evidence A) $(1,88)$. Moreover, the use of an oral corticosteroid trial to determine corticosteroid-responsive subjects was abandoned many years ago as such a phenotype cannot be distinguished $(1,89)$.

\section{Phosphodiesterase inhibitors}

The oral phosphodiesterase 4 (PDE-4) inhibitors are an 
alternative class of drugs for COPD. These drugs increase concentrations of cyclic adenosine monophosphate (cAMP) by inhibiting its PDE-mediated breakdown. Roflumilast, a once daily oral medication, is the only PDE-4 inhibitor currently approved by the US Food and Drug Administration.

A number of trials have been performed using Roflumilast or Cilomilast in the management of COPD. A Cochrane review concluded that this class of drugs demonstrated small, but significant improvement in lung function $\left(\mathrm{FEV}_{1}\right.$ mean difference of $\left.45 \mathrm{~mL}\right)$, and reduced the likelihood of exacerbation (OR 0.77; $95 \%$ CI, 0.71-0.83), which translated into six additional people remaining exacerbation free, for every 100 people treated in the trial period (Evidence A). They were found to have little effect on either quality of life or symptoms. However, non-serious side effects are common, especially gastrointestinal symptoms and headaches, with Roflumilast being associated with weight loss, insomnia and depressive symptoms. Of note, is that the treatment groups of many controlled trials were more likely to withdraw due to intolerable side-effects (90).

Patients most likely to benefit from Roflumilast have been identified as those with more severe COPD who have chronic bronchitis with frequent exacerbations ( 2 or more per year) (91). Using Roflumilast in addition to other bronchodilators in this population has shown mixed results, with a recent study failing to demonstrate a reduction in moderate and/or severe exacerbations (92). This has to be compared to a previous trial in a similar population group, which showed a small, but statistically significant reduction in exacerbations and hospital admissions when added to inhaled therapies (93), with both studies demonstrating high numbers of non-serious side effects, and almost twice as many discontinuations.

Use of PDE-4 inhibitors in acute exacerbations of COPD has not been demonstrated to be of benefit, and a recent study showed equivocal results in airway inflammation (94).

\section{Alpha-1 antitrypsin augmentation therapy}

Intravenous alpha-1 antitrypsin augmentation is recommended (Evidence B) in non-smoking patients, known with alpha-1 deficiency with an FEV1 35-60\%. The cost of medication limits the availability (1).

\section{Mucolytics and mucokinetic agents}

A Cochrane review of 26 studies (19 using $\mathrm{N}$-acetylcysteine), concluded that mucolytics may produce a small reduction in acute exacerbations, and may have a small beneficial effect on overall quality of life, while appearing to be relatively safe (95) (Evidence B). A recent randomized trial of Lysozyme (a mucolytic) failed to show benefit in terms of exacerbation rate, or improvement in $\mathrm{FEV}_{1}$ or CAT (symptom) scores, but appeared well tolerated (96).

Based on the heterogeneity of studies, and reduced benefit in more recent studies, we do not recommend the routine use of mucolytics or mucokinetics for COPD. It is unclear whether certain phenotypes will be identified in the future, which may benefit more from these therapies.

\section{Airway clearance}

A Cochrane review showed airway clearance techniques to be safe in acute exacerbations of COPD, but the effects although significant were small, and based on small studies of low quality. Reported effects included a decreased need for ventilation and reduced hospital stay, but no short-term improvement in quality of life or long-term decrease in exacerbations. Airway clearance techniques in stable COPD appeared to have no short-term benefit on exacerbations, but did improve quality of life, and may reduce hospitalization in the long-term (97).

A further systematic review showed airway clearance techniques did not improve resting lung function or gas exchange, while continuous (5 $\mathrm{min}$ ) chest wall percussion reduced $\mathrm{FEV}_{1}$. However, in patients with copious secretions, mechanical vibration and positive expiratory pressure (PEP) mask therapy could increase sputum clearance, while the latter as well as intrapulmonary percussive ventilation (IPV) may reduce requirements for NIPPV in hypercapnic respiratory failure (98).

We therefore do not recommend stand-alone, routine airway clearance for outpatient COPD management, and although safe, evidence does not support routine airway clearance in acute exacerbations. However, selected patients who present with excessive secretions or an ineffective cough may benefit from airway clearance interventions. If required, airway clearance using PEP techniques have greater benefit over other airway clearance methods.

\section{Venesection}

Polycythaemia occurs in about $6 \%$ of COPD patients (99). This secondary polycythaemia has not been robustly shown to be associated with worse outcomes in COPD (99). 
Physiological studies have shown that phlebotomy in polycythaemic patients with COPD increases the maximum achievable workload, primarily due to an increased cardiac output (100), as well as lowers viscosity with a corresponding improvement in cerebral perfusion and mental function $(101,102)$. Patients with polycythaemia should be referred for investigation and treatment including venesection.

\section{Assessment of response to therapy}

The $\mathrm{FEV}_{1}$ is useful as a diagnostic and prognostic tool and is also of value in monitoring disease progression. It is not as useful for assessing response to treatment. Other lung function measurements to monitor response include inspiratory capacity (IC), residual volume (RV) and functional residual capacity (FRC) (103). The response to treatment can also be gauged by the improvement in dyspnoea, and the mMRC dyspnoea scale (Figure 1) is used to quantify the degree of dyspnoea. The $6 \mathrm{MWD}$ test can be used to assess response to therapy as well (Appendix B).

\section{PR and education}

$\mathrm{PR}$ is a comprehensive interdisciplinary tailored intervention including exercise and education for people with COPD with the aim of promoting physical and psychological well-being, self-efficacy, health enhancing behaviours. PR has consistently shown to increase functional capacity, decrease dyspnoea and improve quality of life $(104,105)$. Programmes usually involve structured exercise training, education, nutritional intervention, and psychosocial support. PR does not improve lung function, lung mechanics or gas exchange, but targets the systemic manifestations of COPD such as sarcopenia and deconditioning. Participants of such programmes undergo a comprehensive assessment by their doctor and physiotherapist, in order to tailor the programme to their individual needs (106).

Underlying medical conditions need to be adequately managed and medications should be optimised. A minimum of 20 sessions should be given at least three times per week to achieve physiologic benefits; twice weekly supervised plus one unsupervised home session may also be acceptable $(107,108)$. There is insufficient evidence of benefit currently to recommend the use of hybrid models of PR including telehealth (105). Rehabilitation can be undertaken in resource-limited settings using supervised walking as a major component, however there is a need to develop contextualised recommendations in resource limited settings.

\section{Prevention and treatment of acute exacerbations of COPD}

\section{Definition, natural history and diagnosis of exacerbations}

An exacerbation is defined as an increase in symptoms of COPD above the usual day-to-day variation experienced by the patient and that necessitates a change in treatment. Exacerbations vary in both severity and frequency. They can be classified as:

(I) Mild-those needing additional short-acting bronchodilators (SABDs) only;

(II) Moderate- those needing SABDs and antibiotics +/- oral corticosteroids;

(III) Severe-those needing hospitalisation or emergency room visits.

Exacerbations severely affect quality of life, may be associated with permanent worsening of COPD, account for a large percentage of the direct costs associated with the treatment of COPD, accelerate disease progression and increase mortality. The most common cause of exacerbations is tracheobronchial infections, usually viral in aetiology.

Acute exacerbations must be distinguished from other diseases and complications of COPD (including pneumonia, pneumothorax, congestive heart failure, arrhythmias and pulmonary embolism) that require alternative treatment. When exacerbations are associated with features of infection (pyrexia and purulent sputum), the presence of pneumonia and other forms of lower respiratory infection should be excluded using a chest radiograph. The aim of therapy for acute exacerbations is to prevent further exacerbations and to minimise the duration and severity of the current exacerbation.

\section{Prevention of exacerbations}

The following measures have been shown to reduce the frequency and/or severity of COPD exacerbations (Evidence A) (1):

* Smoking cessation;

* Prevention of respiratory infections (influenza and pneumococcal vaccination);

* Bronchodilator treatment;

* ICS;

* Roflumilast;

* PR;

* Long-term macrolide therapy. 


\section{Management of exacerbations $(1,2,47)$}

An exacerbation can be managed in either an outpatient or inpatient setting depending on severity. $80 \%$ or more of exacerbations are manageable on an outpatient basis.

\section{Bronchodilators}

Short-acting inhaled $\beta_{2}$ agonists are the $1^{\text {st }}$ choice and they may be combined with short-acting anticholinergics. Nebulisations with short-acting bronchodilators may be given 4-hourly (or as often as every 30-60 minutes or continuously in severe cases). Multiple actuations of an MDI delivered via a large $(>500 \mathrm{~mL})$ spacer device may be as effective as nebulisation.

Should there be an inadequately sustained response to the above treatment, oral or intravenous theophylline may be used. However, significant side-effects with the methylxanthines may be anticipated.

\section{Corticosteroids}

Corticosteroids should preferably be given orally (as effective as intravenous administration). A daily dose of $30-40 \mathrm{mg}$ prednisone for 5 days is recommended (maximum 7) (109). Tapering is not required. Systemic corticosteroids reduce recovery time and hospitalization duration (Evidence A).

\section{Antibiotics (see Appendix C, Table S1)}

These should be prescribed when there is evidence of a severe exacerbation (as evidenced by the 3 cardinal symptoms of increased sputum volume, sputum purulence and increased dyspnoea) or in those who require ventilation (Evidence B) (1). Sputum gram-stain may be helpful by confirming the presence of bacterial organisms but is not an essential investigation. The organisms most commonly involved are Streptococcus pneumoniae, Haemophilus influenzae and Moraxella catarrbalis. With the increasing appearance of penicillin- and macrolide-resistant pneumococci, and beta-lactamase-mediated resistance of $H$. influenzae and $M$. catarrbalis, local sensitivity data should be considered when choosing an antibiotic. Macrolides should be avoided in areas where there are high levels of resistance. Alternatives are amoxicillin/clavulanate, cefuroxime, or fluoroquinolones. The oral route of administration is preferred except in severe illness. The duration of treatment should be 5-7 days (Evidence A).

\section{Oxygen therapy}

Oxygen should be started at $24 \%$ or 1-2 L/minute by nasal cannula. Increases should be gradual to avoid carbon dioxide narcosis. This should be guided by blood gas analysis or by the level of consciousness if blood gases are not available. The aim should be to maintain the oxygen saturation between $88-92 \%$.

\section{Indications for hospitalisation}

Severe COPD and or any of the following features:

* Sustained failure to improve on outpatient management;

* Inability to walk between rooms (where previously mobile);

* Family and/or physician unable to manage the patient at home;

* High-risk co-morbid condition, whether pulmonary (e.g., pneumonia) or non-pulmonary;

* Prolonged progressive worsening of symptoms before emergency visit;

* Altered mentation;

* Worsening hypoxaemia and new or worsening hypercapnia;

* New onset arrhythmia;

* Elderly or frail patient;

* New or worsening right-sided cardiac failure unresponsive to outpatient management.

\section{Indications for ICU admission}

Pre-conditions for ICU admission:

* Satisfactory functional status before the exacerbation (patient coped with activities of daily living); if not known, the patient should be given the benefit of the doubt.

* Possible need for mechanical ventilation, i.e., $\mathrm{PaO}_{2}$ $<6.7 \mathrm{kPa}(50 \mathrm{mmHg})$ on room air, arterial blood $\mathrm{pH}<7.3$, and confusion.

* The presence of a reversible factor. Examples are infections, bronchospasm, oxygen-induced carbon dioxide narcosis, sedative administration, heart failure or other associated illnesses.

\section{Ventilatory support}

Ventilatory support must be considered for the patient with one or more of the following features:

* Exhaustion, confusion, coma;

- $\quad \mathrm{pH}<7.3$ and declining (respiratory acidosis);

* Respiratory or cardiac arrest;

* Inability to clear secretions.

Modalities of ventilatory support include invasive 
(mechanical ventilation) and non-invasive continuous positive airways pressure (CPAP) or BiPAP techniques. Patients considered suitable for non-invasive ventilation (NIV) are those who are able to protect their airway and clear their airway secretions. Indications for NIV include the following (all criteria should be met):

* Respiratory rate $>30$ breaths/minute;

* $\mathrm{pH}<7.35$;

- $\quad \mathrm{PCO}_{2}>6.7 \mathrm{kPa}(>50 \mathrm{mmHg})$;

- $\mathrm{PaO}_{2}<6.7 \mathrm{kPa}$ (<50 mmHg) on room air.

Contra-indications to NIV include haemodynamic instability, decreased level of consciousness or poor cooperation, vomiting and excessive secretions. Appearance of any of these features in a patient undergoing NIV who still needs ventilation is an indication for intubation and mechanical ventilation.

Non-invasive positive pressure ventilation in acute exacerbations has been shown to improve blood gases and $\mathrm{pH}$, reduce in-hospital mortality, decrease the need for invasive mechanical ventilation, and decrease the length of hospital stay (Evidence A). High-flow nasal oxygen therapy may be considered as an alternative to NIV in patients with acute exacerbations of COPD. However, there is currently only limited evidence for this indication (110).

\section{Adjunct therapies}

* Appropriate fluid balance including the judicious use of diuretics where clinically indicated;

* Nutrition should be carefully monitored;

* Smoking cessation must be emphasized during the exacerbation;

* Prophylaxis for thromboembolism should be instituted as patients are at high risk for deep venous thrombosis and pulmonary embolism.

\section{Prevention and treatment of complications}

The main complications include right heart failure, severe exacerbations, pulmonary embolism, pneumothorax, erythrocytosis and chronic respiratory failure.

\section{The management of right heart failure}

* Identify and treat the precipitating cause. In COPD, this may include an acute respiratory infection, worsening airflow obstruction (review bronchodilator and other treatment) or worsening hypoxaemia from additional factors such as re-location to higher altitude or a thrombo-embolic event.

* Correction of hypoxaemia with long-term oxygen as indicated under long-term oxygen therapy (LTOT), see paragraph 10.3) (Evidence D).

- Diuretics (e.g., hydrochlorothiazide or furosemide)

* Digoxin must be avoided except in the presence of atrial fibrillation and/or left ventricular dysfunction/ failure (Evidence $\mathrm{C}$ ).

* ACE inhibitors and calcium antagonists are not indicated for the management of cor pulmonale or right ventricular failure (Evidence B).

* Prophylaxis with subcutaneous heparin to prevent deep vein thrombosis during periods of exacerbation or prolonged immobilisation (Evidence A).

* Chronic treatment with warfarin needs to be considered in COPD patients with atrial fibrillation or thrombo-embolic complications (Evidence A). There is no evidence of benefit when used routinely in patients with cor pulmonale secondary to COPD (Evidence C).

Cardioselective beta-blockers are preferred if required for management of atrial fibrillation or left sided heart failure (Evidence C) (1).

\section{Pneumothorax}

The development of a spontaneous pneumothorax must be considered when patients with stable COPD suddenly deteriorate, as patients with respiratory impairment tolerate even a small pneumothorax poorly.

\section{Long-term oxygen therapy (LTOT)}

The full benefit is only evident in patients with persistent hypoxaemia (with or without hypercapnia) in the stable phase of COPD. In such patients, it has been shown to reduce the complications of respiratory and right heart failure and to improve survival. Patients with COPD and moderate exercise-induced oxygen desaturation $\left(\mathrm{SpO}_{2} \geq 80 \%\right.$ for $\geq 5$ minutes and $<90 \%$ for $\geq 10$ s during a 6 -minute walk test) should not be prescribed LTOT as benefit has not been demonstrated in this group of patients (111).

\section{Indications for LTOT}

* Stable, severe COPD (usually but not exclusively with an $\mathrm{FEV}_{1}<1.5 \mathrm{~L}$ and $\mathrm{FEV}_{1} / \mathrm{FVC}<70 \%$ ) on optimal bronchodilator therapy. The decision to prescribe LTOT should only be made once the patient has fully recovered from an acute exacerbation, usually after 
6 weeks).

- Arterial hypoxaemia $\left(\mathrm{PaO}_{2}<7.3 \mathrm{kPa}\right.$ or $55 \mathrm{mmHg}$ at sealevel) or oxygen saturation $<88 \%$ at rest.

- Smoking cessation for $\geq 3$ months.

Hypoxaemia must be confirmed by arterial blood gases performed while the patient is breathing room air. Following exacerbations of COPD, spirometry and $\mathrm{PaO}_{2}$ may continue to improve for up to 3 months. Therefore, these should ideally be checked in all patients on 2 occasions at least 1 month, and preferably 3 months, apart before prescribing LTOT. Continued smoking reduces the efficacy of treatment and is a contra-indication to oxygen therapy. Worsening hypercapnia caused by hypoventilation is an occasional complication of oxygen therapy in patients with severe COPD and hypercapnic respiratory failure. Regular follow-up by a suitably experienced physician and ready access to technical advice, either through a private contractor or a hospital department, must be available. Assessment of adherence is essential.

\section{Oxygen prescription}

Oxygen is administered by facemask or nasal cannula for a total of at least 16 hours per 24-hour day. A flow rate of 1-2 $\mathrm{L} / \mathrm{min}$. is used, the rate being determined in each case by arterial blood gas determinations. Oximetry may be used for follow-up checks. Oxygen can be delivered by oxygen concentrators or by cylinders. Concentrators are more convenient and cost effective but require an electricity source with additional electricity costs. Portable oxygen systems include bottled oxygen with flow-saving devices and portable concentrators. With these systems, patients do not have to be confined to home.

\section{Palliative symptomatic oxygen therapy}

Oxygen given for short periods to relieve breathlessness in hypoxic patients with COPD does not influence the natural progression of the disease and is therefore not routinely recommended. Patients who desaturate at night should be assessed for sleep apnoea and treated appropriately.

\section{Sleep in COPD}

Sleep-related breathing disorders are present in approximately $40 \%$ of patients with COPD (112). Significant night-time hypoxaemia cannot be predicted from measurement of daytime blood gas and pulmonary function tests, but if the daytime $\mathrm{PaO}_{2}$ is $\geq 8 \mathrm{kPa}(60 \mathrm{mmHg})$, nocturnal $\mathrm{SaO}_{2}$ need only be measured if unexplained respiratory failure, cor pulmonale or erythrocytosis are found. Referral for a full sleep study (polysomnography) and a specialised opinion should only be considered if sleepdisordered breathing is suspected (i.e., daytime hypersomnolence and other symptoms of sleep deprivation, or a strong history of loud snoring with apnoeic events). LTOT, prescribed for daytime hypoxaemia, must be used during sleep.

\section{Air travel in patients with severe COPD}

COPD patients who travel by commercial aircraft put themselves at risk for a range of complications. Respiratory incidents comprise $9-10 \%$ of airborne emergencies. Therefore, the need to travel needs to be balanced against the potential risks. Potential travellers with COPD should have stable disease (no recent exacerbations, hospitalisations or acute illnesses). Co-morbid disease increases the risks of in-flight emergencies, i.e., ischaemic heart disease, congestive cardiac failure and cor pulmonale (56\% of all in-flight emergencies).

Potential problems include:

* Hypoxaemia at altitude: stable COPD patients with an oxygen saturation $\left(\mathrm{SaO}_{2}\right)$ of $95 \%$ pre-flight desaturate to about $86 \%$ at a cabin altitude of $2,165 \mathrm{~m}$. This worsens to $78 \%$ with activity.

* Worsening of existing hypoxia at ground level.

* Pulmonary hypertension.

* Worsening discomfort and dyspnoea at altitude.

* Cardiac dysrhythmias.

* Risk of contracting a respiratory infection.

* Pneumothorax from large bullae.

The most practical evaluation includes room air $\mathrm{SaO}_{2}$ measurements pre-flight. If the $\mathrm{SaO}_{2}$ is less than $92 \%$, further assessment is necessary. Available tests are:

* $50 \mathrm{~m}$ walk test. Those who desaturate will require supplemental $\mathrm{O}_{2}$.

* Hypoxic inhalation test. Patients breathe $15 \% \mathrm{FiO}_{2}$ at sea level. Those with significant desaturation will need supplemental $\mathrm{O}_{2}$.

* Hypobaric chamber simulating in-flight conditions. Their limited availability precludes widespread use in assessing patients.

The in-flight requirement would be $2 \mathrm{~L} / \mathrm{min}$ higher than home use, or $2-4 \mathrm{~L} / \mathrm{min}$ if the assessment indicates the need for $\mathrm{O}_{2}$.

\section{Surgery in patient with a diagnosis of COPD}

Post-operative pulmonary complications constitute a 
significant cause of morbidity and mortality. The frequency varies from $2-70 \%$. The complications are atelectasis, infection (bronchitis and pneumonia), respiratory failure necessitating prolonged mechanical ventilation, exacerbation of COPD, bronchospasm and pulmonary embolism.

Stratification of risk for pulmonary complications entails patient-related as well as procedure-related risk factors. Preoperative evaluation depends strongly on taking a thorough history and clinical examination. It is reasonable to perform a preoperative chest radiograph in patients with cardiopulmonary disease and those $>50$ years undergoing high-risk surgery. Pre-operative preparation, optimisation of airway function (bronchodilators, steroids, antibiotics and chest physiotherapy), smoking cessation, weight reduction where applicable, delay of elective surgery if chest infection is present, and patient education on deep breathing exercises, coughing, pain control and incentive spirometry are recommended. Post-operative measures include early mobilisation and ambulation, prophylactic lung expansion manoeuvres, adequate analgesia and prophylaxis against thrombosis.

\section{Surgical interventions for COPD}

Surgical techniques that can improve lung function and symptoms of COPD include:

* $\quad$ Bullectomy;
LVRS;
LT.

\section{Bullectomy}

This may be indicated to decompress adjacent lung parenchyma if there are large localised bullae. This can be performed thoracoscopically and may reduce dyspnoea and improve lung function (Evidence C).

\section{Lung volume reduction}

The aim of lung volume reduction is to achieve volume loss of the targeted, diseased region(s) and to redirect airflow to less affected areas $(113,114)$. Lung volume reduction can be achieved by either surgical or endoscopic techniques. LVRS entails wedge resection of emphysematous tissue. LVRS carries significant morbidity and mortality, but can offer survival benefit and increased exercise capacity in selected patients with predominantly upper-lobe emphysema, an $\mathrm{FEV}_{1}>20 \%, \mathrm{DL}_{\mathrm{CO}}>20 \%$ and low exercise capacity
(Evidence A) (115). There has been a significant decline in the number of LVRS's performed, both locally and internationally. This is mostly because of the modest benefit, strict selection criteria, morbidity and mortality associated with major thoracic surgery in patients with compromised pulmonary and cardiovascular reserves, and the advent of endoscopic lung volume reduction (ELVR) (113). A bullectomy (which can be performed thoracoscopically) is sometimes indicated to decompress adjacent lung parenchyma and potentially improve lung functions in patients with large localised bullae (Evidence C) (1).

ELVR refers to a bronchoscopic procedure which induces volume loss to improve pulmonary mechanics and compliance, thereby reducing the work of breathing. Globally, this technique is increasingly used as treatment for advanced emphysema, with the objective of obtaining similar functional advantages to surgical lung volume reduction, while decreasing risks and costs. The two most commonly used modalities with the largest evidence base are endobronchial valves and coils.

In certain selected patients with severe hyperinflation $(\mathrm{RV}>150 \%)$ and no interlobular collateral ventilation, the unilateral placement of a device with the intention of achieving complete lobar collapse has been shown to significantly increase lung function, quality of life and exercise capacity (Evidence B) (116).

\section{Lung transplantation (LT)}

LT is an established therapy for advanced COPD and can provide extended survival and excellent quality of life. COPD is the most common indication for LT worldwide, accounting for $40 \%$ of all transplants. Access to LT is limited and is currently offered only at major centres in South Africa: Johannesburg and Cape Town (117). The variability in the natural course of COPD can make it difficult to predict when patients should be referred for LT. The BODE index (derived from measurements of body mass index, degree of airflow obstruction, dyspnoea score and exercise capacity) can be used to predict mortality (57); this can be balanced against the risk of the transplant. Data from the International Society for Heart and Lung Transplantation (ISHLT) registry show a median survival of $\sim 6$ years for patients who undergo transplantation for COPD (118).

Suitable patients may be referred for LT when the:

* Disease is progressive despite optimisation of pharmacological management, PR and oxygen 
therapy;

* Patient is not a candidate for endoscopic or surgical LVRS;

* FEV1 $<25 \%$ of the predicted volume;

* BODE index $\geq 5$;

* There is established hypoxaemic or hypercapnic respiratory failure.

\section{Acknowledgments}

Several components of this guideline represent an unchanged standard of care and are based on the previous edition of the South African Guideline of which Professor ED Bateman was the chief author; his contribution is gratefully acknowledged. We are grateful to the SATS physiotherapy assembly for reviewing the PR recommendations. The guidelines were funded by the South African Thoracic Society.

\section{Footnote}

Conflicts of Interest: RN van Zyl-Smit has received honoraria for academic talks and advisory boards from Astra Zeneca, GSK, ASPEN, Novartis, Cipla, MSD, Roche, Pfizer, Adcock Ingram. MS Abdool-Gaffar has received honoraria for talks from Novartis, Astra Zeneca, GSK/Aspen and Pfizer. C Smith has received honoraria for academic talks and advisory boards from Astra Zeneca, GSK/Aspen, Novartis, Cipla. CF Koegelenberg has received honoraria for academic talks and advisory boards from Astra Zeneca. $\mathrm{K}$ Dheda has received honoraria for academic symposia, membership of advisory boards, and/ or grant support from Astra Zeneca, GSK, Novartis, Adcock Ingram, Nycomed Takeda, Cipla, and MSD. B Allwood has received honoraria for academic talks from Novartis. A Goolam-Mahomed has received honoraria for Academic talks, advisory boards and congress attendance from Astra-Zeneca and GSK-Aspen. ML Wong has received honoraria for academic talks from AstraZeneca, Cipla, Novartis, Boehringer-Ingelheim, MSD. UG Lalloo has received honoraria for academic symposia, membership of advisory boards for Astra-Zeneca, Aspen GSK, CIPLA, Novartis, Adcock Ingram, Nycomed Takeda and MSD. G Calligaro has received honoraria for academic talks from Astra-Zeneca, Novartis.

Ethical Statement: The authors are accountable for all aspects of the work in ensuring that questions related to the accuracy or integrity of any part of the work are appropriately investigated and resolved.

\section{References}

1. GOLD. Global strategy for the diagnosis, management, and prevention of chronic obstructive pulmonary disease. Available online: http://www.goldcopd.org/uploads/users/ files/GOLD_Report2019.pdf2019

2. Bateman ED, Feldman C, O'Brien J, et al. Guideline for the management of chronic obstructive pulmonary disease (COPD): 2004 revision. S Afr Med J 2004;94:559-75.

3. Adeloye D, Chua S, Lee C, et al. Global and regional estimates of COPD prevalence: Systematic review and meta-analysis. J Glob Health 2015;5:020415.

4. Adeloye D, Basquill C, Papana A, et al. An estimate of the prevalence of COPD in Africa: a systematic analysis. COPD 2015;12:71-81.

5. Buist AS, McBurnie MA, Vollmer WM, et al. International variation in the prevalence of COPD (the BOLD Study): a population-based prevalence study. Lancet 2007;370:741-50.

6. Murray CJ, Lopez AD. Alternative projections of mortality and disability by cause 1990-2020: Global Burden of Disease Study. Lancet 1997;349:1498-504.

7. Jemal A, Ward E, Hao Y, et al. Trends in the leading causes of death in the United States, 1970-2002. JAMA 2005;294:1255-9.

8. van Zyl Smit RN, Pai M, Yew WW, et al. Global lung health: the colliding epidemics of tuberculosis, tobacco smoking, HIV and COPD. Eur Respir J 2010;35:27-33.

9. Stoller JK, Aboussouan LS. Alpha1-antitrypsin deficiency. Lancet 2005;365:2225-36.

10. Cho MH, McDonald ML, Zhou X, et al. Risk loci for chronic obstructive pulmonary disease: a genome-wide association study and meta-analysis. Lancet Respir Med 2014;2:214-25.

11. Repapi E, Sayers I, Wain LV, et al. Genome-wide association study identifies five loci associated with lung function. Nat Genet 2010;42:36-44.

12. Hersh CP, Hokanson JE, Lynch DA, et al. Family history is a risk factor for COPD. Chest 2011;140:343-50.

13. Barker DJ, Godfrey KM, Fall C, et al. Relation of birth weight and childhood respiratory infection to adult lung function and death from chronic obstructive airways disease. BMJ 1991;303:671-5.

14. Lawlor DA, Ebrahim S, Davey Smith G. Association of birth weight with adult lung function: findings from the British Women's Heart and Health Study and a meta- 
analysis. Thorax 2005;60:851-8.

15. Silverman EK, Weiss ST, Drazen JM, et al. Genderrelated differences in severe, early-onset chronic obstructive pulmonary disease. Am J Respir Crit Care Med 2000;162:2152-8.

16. Burrows B, Knudson RJ, Cline MG, et al. Quantitative relationships between cigarette smoking and ventilatory function. Am Rev Respir Dis 1977;115:195-205.

17. Fletcher C, Peto R. The natural history of chronic airflow obstruction. Br Med J 1977;1:1645-8.

18. Anthonisen NR, Connett JE, Murray RP. Smoking and lung function of Lung Health Study participants after 11 years. Am J Respir Crit Care Med 2002;166:675-9.

19. Rennard SI, Vestbo J. COPD: the dangerous underestimate of 15\%. Lancet 2006;367:1216-9.

20. Eisner MD, Balmes J, Katz PP, et al. Lifetime environmental tobacco smoke exposure and the risk of chronic obstructive pulmonary disease. Environ Health 2005;4:7.

21. Dayal HH, Khuder S, Sharrar R, et al. Passive smoking in obstructive respiratory disease in an industrialized urban population. Environ Res 1994;65:161-71.

22. Tager IB, Ngo L, Hanrahan JP. Maternal smoking during pregnancy. Effects on lung function during the first 18 months of life. Am J Respir Crit Care Med 1995;152:977-83.

23. Joshi M, Joshi A, Bartter T. Marijuana and lung diseases. Curr Opin Pulm Med 2014;20:173-9.

24. Tashkin DP. Effects of marijuana smoking on the lung. Annals of the American Thoracic Society 2013;10:239-47.

25. Becklake MR. Occupational exposures: evidence for a causal association with chronic obstructive pulmonary disease. Am Rev Respir Dis 1989;140:S85-91.

26. Hnizdo E, Sullivan PA, Bang KM, et al. Association between chronic obstructive pulmonary disease and employment by industry and occupation in the US population: a study of data from the Third National Health and Nutrition Examination Survey. Am J Epidemiol 2002;156:738-46.

27. Bruce N, Perez-Padilla R, Albalak R. Indoor air pollution in developing countries: a major environmental and public health challenge. Bull World Health Organ 2000;78:1078-92.

28. Salvi SS, Barnes PJ. Chronic obstructive pulmonary disease in non-smokers. Lancet. 2009;374:733-43.

29. Fullerton DG, Bruce N, Gordon SB. Indoor air pollution from biomass fuel smoke is a major health concern in the developing world. Trans R Soc Trop Med Hyg
2008;102:843-51.

30. Hu G, Zhou Y, Tian J, et al. Risk of COPD from exposure to biomass smoke: a metaanalysis. Chest 2010;138:20-31.

31. van Zyl-Smit RN, Balmes JR. Seeing the Wood for the Trees: Household Air Pollution and Lung Disease. Am J Respir Crit Care Med 2019;199:264-5.

32. Abbey DE, Burchette RJ, Knutsen SF, et al. Longterm particulate and other air pollutants and lung function in nonsmokers. Am J Respir Crit Care Med 1998;158:289-98.

33. Wang M, Aaron CP, Madrigano J, et al. Association Between Long-term Exposure to Ambient Air Pollution and Change in Quantitatively Assessed Emphysema and Lung Function. JAMA 2019;322:546-56.

34. Doiron D, de Hoogh K, Probst-Hensch N, et al. Air pollution, lung function and COPD: results from the population-based UK Biobank study. Eur Respir J 2019;54:1802140.

35. Amaral AF, Coton S, Kato B, et al. Tuberculosis associates with both airflow obstruction and low lung function: BOLD results. Eur Respir J 2015;46:1104-12.

36. Ravimohan S, Kornfeld H, Weissman D, et al. Tuberculosis and lung damage: from epidemiology to pathophysiology. Eur Respir Rev 2018;27:170077.

37. Byrne AL, Marais BJ, Mitnick CD, et al. Tuberculosis and chronic respiratory disease: a systematic review. Int J Infect Dis 2015;32:138-46.

38. Caballero A, Torres-Duque CA, Jaramillo C, et al. Prevalence of COPD in five Colombian cities situated at low, medium, and high altitude (PREPOCOL study). Chest 2008;133:343-9.

39. Idolor LF, DE Guia TS, Francisco NA, et al. Burden of obstructive lung disease in a rural setting in the Philippines. Respirology 2011;16:1111-8.

40. Magitta NF, Walker RW, Apte KK, et al. Prevalence, risk factors and clinical correlates of COPD in a rural setting in Tanzania. Eur Respir J 2018;51:1700182.

41. Allwood BW, Gillespie R, Galperin-Aizenberg M, et al. Obstructive pulmonary disease in patients with previous tuberculosis: Pathophysiology of a community-based cohort. S Afr Med J 2017;107:440-5.

42. Allwood BW, Rigby J, Griffith-Richards S, et al. Histologically confirmed tuberculosis-associated obstructive pulmonary disease. Int J Tuberc Lung Dis 2019;23:552-4.

43. Shaheen SO, Barker DJ, Shiell AW, et al. The relationship between pneumonia in early childhood and impaired lung function in late adult life. Am J Respir Crit Care Med 
1994;149:616-9.

44. Allwood BW, Myer L, Bateman ED. A systematic review of the association between pulmonary tuberculosis and the development of chronic airflow obstruction in adults. Respiration 2013;86:76-85.

45. Morris A, George MP, Crothers K, et al. HIV and chronic obstructive pulmonary disease: is it worse and why? Proc Am Thorac Soc 2011;8:320-5.

46. Bigna JJ, Kenne AM, Asangbeh SL, et al. Prevalence of chronic obstructive pulmonary disease in the global population with HIV: a systematic review and metaanalysis. Lancet Glob Health 2018;6:e193-e202

47. Seemungal T, Harper-Owen R, Bhowmik A, et al. Respiratory viruses, symptoms, and inflammatory markers in acute exacerbations and stable chronic obstructive pulmonary disease. Am J Respir Crit Care Med 2001;164:1618-23.

48. Prescott E, Lange P, Vestbo J. Socioeconomic status, lung function and admission to hospital for COPD: results from the Copenhagen City Heart Study. Eur Respir J 1999;13:1109-14.

49. Celli BR, MacNee W, Force AET. Standards for the diagnosis and treatment of patients with COPD: a summary of the ATS/ERS position paper. Eur Respir J 2004;23:932-46.

50. National Collaborating Centre for Chronic Conditions. Chronic obstructive pulmonary disease. National clinical guideline on management of chronic obstructive pulmonary disease in adults in primary and secondary care. Thorax 2004;59 Suppl 1:1-232.

51. Koegelenberg CF, Swart F, Irusen EM. Guideline for office spirometry in adults, 2012. S Afr Med J 2012;103:52-62.

52. Hanania NA, Sharafkhaneh A, Celli B, et al. Acute bronchodilator responsiveness and health outcomes in COPD patients in the UPLIFT trial. Respir Res 2011;12:6.

53. Quanjer PH, Tammeling GJ, Cotes JE, et al. Lung volumes and forced ventilatory flows. Eur Respir J 1993;6 Suppl 16:5-40.

54. Hankinson JL, Odencrantz JR, Fedan KB. Spirometric reference values from a sample of the general U.S. population. Am J Respir Crit Care Med 1999;159:179-87.

55. Global Lung function Initiative. ERS; 2019 (cited 201930 August 2019). Available online: https://www.ers-education. org/guidelines/global-lung-function-initiative.aspx

56. Koegelenberg CF, Swart F, Irusen EM. Prediction equations for spirometry in South Africa. S Afr Med J 2013;103:597.

57. Celli BR, Cote CG, Marin JM, et al. The body-mass index, airflow obstruction, dyspnea, and exercise capacity index in chronic obstructive pulmonary disease. $\mathrm{N}$ Engl J
Med 2004;350:1005-12.

58. Tønnesen P, Carrozzi L, Fagerstrom KO, et al. Smoking cessation in patients with respiratory diseases: a high priority, integral component of therapy. Eur Respir J 2007;29:390-417.

59. van Zyl-Smit RN, Allwood B, Stickells D, et al. South African tobacco smoking cessation clinical practice guideline. S Afr Med J 2013;103:869-76.

60. Kohansal R, Martinez-Camblor P, Agusti A, et al. The natural history of chronic airflow obstruction revisited: an analysis of the Framingham offspring cohort. Am J Respir Crit Care Med 2009;180:3-10.

61. Anthonisen NR, Skeans MA, Wise RA, et al. The effects of a smoking cessation intervention on 14.5-year mortality: a randomized clinical trial. Ann Intern Med 2005;142:233-9.

62. Tadzimirwa GY, Day C, Esmail A, et al. Challenges for dedicated smoking cessation services in developing countries. S Afr Med J 2019;109:431-6.

63. Kew KM, Dias S, Cates CJ. Long-acting inhaled therapy (beta-agonists, anticholinergics and steroids) for COPD: a network meta-analysis. Cochrane Database Syst Rev 2014;3:CD010844.

64. Farne HA, Cates CJ. Long-acting beta2-agonist in addition to tiotropium versus either tiotropium or long-acting beta2-agonist alone for chronic obstructive pulmonary disease. Cochrane Database Syst Rev 2015;10:CD008989.

65. Chong J, Karner C, Poole P. Tiotropium versus longacting beta-agonists for stable chronic obstructive pulmonary disease. Cochrane Database Syst Rev 2012;9:CD009157.

66. Kew KM, Mavergames C, Walters JA. Long-acting beta2-agonists for chronic obstructive pulmonary disease. Cochrane Database Syst Rev 2013;10:CD010177.

67. Cheyne L, Irvin-Sellers MJ, White J. Tiotropium versus ipratropium bromide for chronic obstructive pulmonary disease. Cochrane Database Syst Rev 2015;(9):CD009552.

68. Ni H, Soe Z, Moe S. Aclidinium bromide for stable chronic obstructive pulmonary disease. Cochrane Database Syst Rev 2014;9:CD010509.

69. Karner C, Chong J, Poole P. Tiotropium versus placebo for chronic obstructive pulmonary disease. Cochrane Database Syst Rev 2014;7:CD009285.

70. Yang IA, Clarke MS, Sim EH, et al. Inhaled corticosteroids for stable chronic obstructive pulmonary disease. Cochrane Database Syst Rev 2012;7:CD002991.

71. Kew KM, Seniukovich A. Inhaled steroids and risk of pneumonia for chronic obstructive pulmonary disease. Cochrane Database Syst Rev 2014;3:CD010115. 
72. Wedzicha JA, Banerji D, Chapman KR, et al. IndacaterolGlycopyrronium versus Salmeterol-Fluticasone for COPD. N Engl J Med 2016;374:2222-34.

73. Lipson DA, Barnhart F, Brealey N, et al. Once-Daily Single-Inhaler Triple versus Dual Therapy in Patients with COPD. N Engl J Med 2018;378:1671-80.

74. Moayyedi P, Congleton J, Page RL, et al. Comparison of nebulised salbutamol and ipratropium bromide with salbutamol alone in the treatment of chronic obstructive pulmonary disease. Thorax 1995;50:834-7.

75. Gross N, Tashkin D, Miller R, et al. Inhalation by nebulization of albuterol-ipratropium combination (Dey combination) is superior to either agent alone in the treatment of chronic obstructive pulmonary disease. Dey Combination Solution Study Group. Respiration 1998;65:354-62.

76. Ram FS, Jones PW, Castro AA, et al. Oral theophylline for chronic obstructive pulmonary disease. Cochrane Database Syst Rev 2002;(4):CD003902.

77. Tee AK, Koh MS, Gibson PG, et al. Long-acting beta2agonists versus theophylline for maintenance treatment of asthma. Cochrane Database Syst Rev 2007;(3):CD001281.

78. Kim JH, Park JS, Kim KH, et al. Inhaled corticosteroid is associated with an increased risk of TB in patients with COPD. Chest 2013;143:1018-24.

79. Brassard P, Suissa S, Kezouh A, et al. Inhaled corticosteroids and risk of tuberculosis in patients with respiratory diseases. Am J Respir Crit Care Med 2011;183:675-8.

80. Dong YH, Chang CH, Lin Wu FL, et al. Use of inhaled corticosteroids in patients with COPD and the risk of TB and influenza: A systematic review and meta-analysis of randomized controlled trials. a systematic review and meta-analysis of randomized controlled trials. Chest 2014;145:1286-97.

81. Shaw JA, Irusen EM. Inhaled corticosteroids in COPD: Personalising the therapeutic choice. African Journal of Thoracic and Critical Care Medicine 2018;24:19-25.

82. Anzueto A, Ferguson GT, Feldman G, et al. Effect of fluticasone propionate/salmeterol (250/50) on COPD exacerbations and impact on patient outcomes. COPD 2009;6:320-9.

83. Ferguson GT, Anzueto A, Fei R, et al. Effect of fluticasone propionate/salmeterol (250/50 microg) or salmeterol (50 microg) on COPD exacerbations. Respir Med 2008;102:1099-108.

84. Sharafkhaneh A, Southard JG, Goldman M, et al. Effect of budesonide/formoterol pMDI on COPD exacerbations: a double-blind, randomized study. Respir Med 2012;106:257-68.

85. Watz H, Tetzlaff K, Wouters EF, et al. Blood eosinophil count and exacerbations in severe chronic obstructive pulmonary disease after withdrawal of inhaled corticosteroids: a post-hoc analysis of the WISDOM trial. Lancet Respir Med 2016;4:390-8.

86. Magnussen H, Disse B, Rodriguez-Roisin R, et al. Withdrawal of inhaled glucocorticoids and exacerbations of COPD. N Engl J Med 2014;371:1285-94.

87. Chapman KR, Hurst JR, Frent SM, et al. LongTerm Triple Therapy De-escalation to Indacaterol/ Glycopyrronium in Patients with Chronic Obstructive Pulmonary Disease (SUNSET): A Randomized, DoubleBlind, Triple-Dummy Clinical Trial. Am J Respir Crit Care Med 2018;198:329-39.

88. Walters JA, Walters EH, Wood-Baker R. Oral corticosteroids for stable chronic obstructive pulmonary disease. Cochrane Database Syst Rev 2005;(3):CD005374.

89. Burge PS, Calverley PM, Jones PW, et al. Prednisolone response in patients with chronic obstructive pulmonary disease: results from the ISOLDE study. Thorax 2003;58:654-8.

90. Chong J, Leung B, Poole P. Phosphodiesterase 4 inhibitors for chronic obstructive pulmonary disease. Cochrane Database Syst Rev 2013;11:CD002309.

91. Calverley PM, Rabe KF, Goehring UM, et al. Roflumilast in symptomatic chronic obstructive pulmonary disease: two randomised clinical trials. Lancet 2009;374:685-94.

92. Martinez FJ, Rabe KF, Sethi S, et al. Effect of Roflumilast and Inhaled Corticosteroid/Long-Acting beta2-Agonist on Chronic Obstructive Pulmonary Disease Exacerbations (RE(2)SPOND). A Randomized Clinical Trial. Am J Respir Crit Care Med 2016;194:559-67.

93. Martinez FJ, Calverley PM, Goehring UM, et al. Effect of roflumilast on exacerbations in patients with severe chronic obstructive pulmonary disease uncontrolled by combination therapy (REACT): a multicentre randomised controlled trial. Lancet 2015;385:857-66.

94. Mackay AJ, Patel ARC, Singh R, et al. Randomized Double-Blind Controlled Trial of Roflumilast at Acute Exacerbations of Chronic Obstructive Pulmonary Disease. Am J Respir Crit Care Med 2017;196:656-9.

95. Poole P, Chong J, Cates CJ. Mucolytic agents versus placebo for chronic bronchitis or chronic obstructive pulmonary disease. Cochrane Database Syst Rev 2015;(7):CD001287.

96. Fukuchi Y, Tatsumi K, Inoue H, et al. Prevention of 
COPD exacerbation by lysozyme: a double-blind, randomized, placebo-controlled study. Int J Chron Obstruct Pulmon Dis 2016;11:831-8.

97. Osadnik CR, McDonald CF, Jones AP, et al. Airway clearance techniques for chronic obstructive pulmonary disease. Cochrane Database Syst Rev 2012;(3):CD008328.

98. Hill K, Patman S, Brooks D. Effect of airway clearance techniques in patients experiencing an acute exacerbation of chronic obstructive pulmonary disease: a systematic review. Chron Respir Dis 2010;7:9-17.

99. Cote C, Zilberberg MD, Mody SH, et al. Haemoglobin level and its clinical impact in a cohort of patients with COPD. Eur Respir J 2007;29:923-9.

100. Chetty KG, Light RW, Stansbury DW, et al. Exercise performance of polycythemic chronic obstructive pulmonary disease patients. Effect of phlebotomies. Chest 1990;98:1073-7.

101. York EL, Jones RL, Menon D, et al. Effects of secondary polycythemia on cerebral blood flow in chronic obstructive pulmonary disease. Am Rev Respir Dis 1980;121:813-8.

102. Bornstein R, Menon D, York E, et al. Effects of venesection on cerebral function in chronic lung disease. Can J Neurol Sci 1980;7:293-6.

103.Marin JM, Carrizo SJ, Gascon M, et al. Inspiratory capacity, dynamic hyperinflation, breathlessness, and exercise performance during the 6-minute-walk test in chronic obstructive pulmonary disease. Am J Respir Crit Care Med 2001;163:1395-9.

104.McCarthy B, Casey D, Devane D, et al. Pulmonary rehabilitation for chronic obstructive pulmonary disease. Cochrane Database Syst Rev 2015;(2):CD003793.

105.GOLD. Global Strategy for the Diagnosis, Management and Prevention of COPD, Global Initiative for Chronic Obstructive Lung Disease (GOLD) 2016. Available online: http://goldcopd.org/2019

106. Wouters EFM, Wouters B, Augustin IML, et al. Personalised pulmonary rehabilitation in COPD. Eur Respir Rev 2018;27:170125.

107. Spruit MA, Singh SJ, Garvey C, et al. An official American Thoracic Society/European Respiratory Society statement: key concepts and advances in pulmonary rehabilitation. Am J Respir Crit Care Med 2013;188:e13-64.

108. Koegelenberg CF, Noor F, Bateman ED, et al. Efficacy of varenicline combined with nicotine replacement therapy vs varenicline alone for smoking cessation: a randomized clinical trial. JAMA 2014;312:155-61.

109.Leuppi JD, Schuetz P, Bingisser R, et al. Short-term vs conventional glucocorticoid therapy in acute exacerbations of chronic obstructive pulmonary disease: the REDUCE randomized clinical trial. JAMA 2013;309:2223-31.

110.Sun J, Li Y, Ling B, et al. High flow nasal cannula oxygen therapy versus non-invasive ventilation for chronic obstructive pulmonary disease with acute-moderate hypercapnic respiratory failure: an observational cohort study. Int J Chron Obstruct Pulmon Dis 2019;14:1229-37.

111.Long-Term Oxygen Treatment Trial Research G, Albert RK, Au DH, et al. A Randomized Trial of Long-Term Oxygen for COPD with Moderate Desaturation. N Engl J Med 2016;375:1617-27.

112. Chen R, Tian JW, Zhou LQ, et al. The relationship between sleep quality and functional exercise capacity in COPD. Clin Respir J 2016;10:477-85.

113. Koegelenberg CF, Slebos DJ, Shah PL, et al. Time for the Global Rollout of Endoscopic Lung Volume Reduction. Respiration 2015;90:430-40.

114. Koegelenberg CF, Theron J, Bruwer JW, et al. Endoscopic lung volume reduction in severe emphysema. S Afr Med J 2015;105:721-3.

115. Fishman A, Martinez F, Naunheim K, et al. A randomized trial comparing lung-volume-reduction surgery with medical therapy for severe emphysema. N Engl J Med 2003;348:2059-73.

116. Klooster K, ten Hacken NH, Hartman JE, et al. Endobronchial Valves for Emphysema without Interlobar Collateral Ventilation. N Engl J Med 2015;373:2325-35.

117. Calligaro GL, Brink J, Williams P, et al. Lung transplantation in South Africa : indications, outcomes and disease-specific referral guidelines. African Journal of Thoracic and Critical Care Medicine 2018;24:118-22.

118. Khush KK, Cherikh WS, Chambers DC, et al. The International Thoracic Organ Transplant Registry of the International Society for Heart and Lung Transplantation: Thirty-fifth Adult Heart Transplantation Report-2018; Focus Theme: Multiorgan Transplantation. J Heart Lung Transplant 2018;37:1155-68.

Cite this article as: Abdool-Gaffar MS, Calligaro G, Wong ML, Smith C, Lalloo UG, Koegelenberg CF, Dheda K, Allwood BW, Goolam-Mahomed A, van Zyl-Smit RN. Management of chronic obstructive pulmonary disease-A position statement of the South African Thoracic Society: 2019 update. J Thorac Dis 2019;11(11):4408-4427. doi: 10.21037/ jtd.2019.10.65 


\section{Appendix A Process of guideline revision}

The Council of the South African Thoracic Society resolved to revise the 2011 COPD guideline and appointed a convenor Dr Abdool-Gaffar and co-Chair Prof van Zyl-Smit to lead the editorial committee to revise the document. Membership of the guideline working group comprised representatives from the academic sector and private practice. The editorial committee identified areas of the guideline that required revision and commissioned members of the working group to prepare reviews of new data in these areas, with particular reference to the content and evidence grading of the latest version of the Global Obstructive Lung Disease Guideline [2019]. The revised document was compiled by the editorial board and circulated to the guideline committee for further comment. These comments were considered by the editorial committee, and the final draft was then completed and approved by the Council of the South African Thoracic Society.

\section{Appendix B The 6-minute walk test (6MWT) (75)}

The 6MWT is a composite and repeatable test of lung, heart and muscle function. Measurement of specific exercise-induced outcomes are an extremely important adjunct to clinical and lung function evaluation. The $6 \mathrm{MWT}$ does not correlate well with $\mathrm{FEV}_{1}$ but relates to the degree of exercise-induced hyperinflation of COPD patients and is used extensively as a prognostic indicator for patients with COPD, interstitial lung disease or pulmonary hypertension. It provides better insight into the degree of exercise impairment compared with single evaluations such as spirometry or an ECG.

The $6 \mathrm{MWT}$ has to be conducted under supervision of a trained medical or paramedical person who can recognise untoward exercise-induced symptoms. Prior to the test, patients have to be evaluated to rule out uncontrolled hypertension, ischaemic heart disease, arrhythmias and heart failure that may complicate the assessment or endanger the patient. These conditions need adequate treatment before the 6MWT can be conducted. Patients with lower limb arthritis or claudication and those who are mentally challenged or old and infirm will not perform the test adequately. It can be conducted in any facility that has the necessary resuscitation equipment and a straight, flat surface of 30 meters or a treadmill. Prior to the test, patients need to be counselled to motivate them to achieve the greatest distance. They also need to be informed that they may rest during the test but that it will be recorded as part of their $6 \mathrm{MWT}$ walk time. All COPD patients need to use their bronchodilators before attempting the $6 \mathrm{MWT}$, and they should not be exercised during an infective episode or if they are in the immediate recovery phase of an exacerbation.

A baseline ECG is done and should be repeated after the first effort to record any asymptomatic exercise-induced ischaemic changes. The oxygen saturation of blood should be measured before and after the test. Determination of pulse rate, blood pressure and respiratory rate along with the blood oxygen saturation level should be recorded before and after the test. A level in the latter $<90 \%$ or a decline $>5 \%$ will identify those patients who will require oxygen during the test. Patients' opinions as to their degree of exhaustion need to be recorded on a Borg scale card which provides a semi-quantitative estimation of fatigue and dyspnoea. Recovery time should be noted by measuring the respiratory and heart rates at 3 and 5 minutes after the test. Repeatability of the 6MWD (distance) of $10 \%$ should be achieved. In this respect, a second or, if required, even a third 6MWT should be conducted after periods of rest of up to 20 minutes. The 6 MWT should be discontinued in patients who complain of chest pain, intolerable dyspnoea or leg cramps, or appear to be staggering or have an ashen or pale appearance. A mean value for males of 464 metres and 430 metres for females is the standard for a healthy American population. A post-intervention improvement of 54 meters above the baseline $6 \mathrm{MWD}$ has been found to represent a clinically meaningful improvement in COPD patients who undergo rehabilitation.

\section{Appendix C Antibiotic use in exacerbations of COPD}

Chronic bronchitis, with attendant mucociliary dysfunction and mucus hypersecretion, is the major pathological component that is responsible for the risk of bacterial colonisation and acute infective exacerbations of COPD. 
Table S1 Recommendations for the antibiotic management of acute exacerbations of COPD based on a classification of bronchitis**

\begin{tabular}{|c|c|c|c|}
\hline Diagnosis & Criteria/risk factors & Usual pathogens & Recommended treatment* \\
\hline \multirow{3}{*}{ 1. Simple chronic bronchitis } & $\mathrm{FEV}_{1}>60 \%$ predicted & M. catarrhalis & Amoxycillin-clavulanic acid \\
\hline & Recent increase in sputum & S. pneumoniae & Macrolide/azalide/Ketolide \\
\hline & Volume and purulence & Beta-lactam resistance possible & \\
\hline \multirow{3}{*}{$\begin{array}{l}\text { 2. Complicated chronic } \\
\text { bronchitis }\end{array}$} & $\mathrm{FEV}_{1}<60 \%$ predicted & $\begin{array}{l}\text { Sputum Gram stain and culture } \\
\text { advised }\end{array}$ & $\begin{array}{l}\text { Second or third generation } \\
\text { cephalosporin }\end{array}$ \\
\hline & $\geq 4$ exacerbations/year & & Respiratory fluoroquinolone \\
\hline & $\begin{array}{l}\text { Recent increase in sputum } \\
\text { volume and purulence }\end{array}$ & & \\
\hline \multirow{2}{*}{$\begin{array}{l}\text { 3. Complicated chronic } \\
\text { bronchitis with chronic } \\
\text { bronchial sepsis }\end{array}$} & $\begin{array}{l}\text { X-ray evidence of structural } \\
\text { lung disease }\end{array}$ & Sputum Gram stain & Respiratory fluoroquinolone \\
\hline & & & $\begin{array}{l}\text { Alternative based on result of sputum } \\
\text { culture and culture advised }\end{array}$ \\
\hline
\end{tabular}

*, selection of antibiotic is influenced by knowledge of antibiotic resistance patterns in different areas of the country. ${ }^{* *}$, adapted from Grossman RF. The value of antibiotics and the outcomes of antibiotic therapy in exacerbations of COPD. Chest 1998;113:249-255. COPD, chronic obstructive pulmonary disease; $\mathrm{FEV}_{1}$, forced expiratory volume in one second. 